\title{
OBTENCIÓN DE UN AISLADO PROTEICO DE TORTA DE SACHA INCHI (Plukenetia volubilis L.) Y EVALUACIÓN DE SUS PROPIEDADES TECNO-FUNCIONALES
}

\author{
PROTEIN ISOLATED FROM CAKE OF SACHA INCHI (Plukenetia volubilis L.) \\ AND EVALUATION OF ITS TECHNO-FUNCTIONALS PROPERTIES
}

\author{
${ }^{1}$ Jorge L. Mercado R., ${ }^{1,2}$ Carlos C. A. Elías P., ${ }^{1}$ Gloria J. Pascual C.
}

\begin{abstract}
Resumen
Se evaluó las propiedades tecno-funcionales de un aislado proteico obtenido a partir de torta de sacha inchi (TSI). El aislado proteico de sacha inchi (APSI) fue obtenido usando el método de extracción alcalina y precipitación isoeléctrica. Las variables estudiadas para la extracción proteica fueron: harina desgrasada/solvente, $\mathrm{pH}$, temperatura y tiempo. Los valores de las variables con los que se obtuvo una máxima solubilización fueron: $1: 30,11,50^{\circ} \mathrm{C}$ y $60 \mathrm{~min}$, respectivamente. Las proteínas solubles fueron precipitadas en su punto isoeléctrico ( $\mathrm{pH}$ 6), lavadas, ajustadas a $\mathrm{pH} 7$ y secadas por atomización. Las propiedades tecno-funcionales del APSI que manifestaron valores más elevadas respecto al aislado proteico de soya (SPI) fueron: Solubilidad (máxima a 99,4\% a pH 11 y mínima a 18,7\% a pH 6), Capacidad de Absorción de Aceite (1,39 g aceite/g aislado proteico), Capacidad de Formación de Espuma (55\% a 1\% concentración de aislado proteico y pH 8) y la Estabilidad de Espuma (33,7\% a 1\% de concentración de aislado proteico a pH 8 y 120 min), Capacidad de Emulsificación $(59,1 \%)$. Las propiedades tecno-funcionales con valores bajos fueron: Capacidad de Retención de Agua (1,84 g agua/g aislado proteico) y Capacidad de Gelificación (15\%).
\end{abstract}

Palabras clave: extracción alcalina, extracción de proteínas, precipitación isoeléctrica.

\begin{abstract}
The physico-chemical parameters to obtain a protein isolated from sacha inchi cake (SIC) were determined and subsequently techno-funtionals properties were evaluated. The sacha inchi protein isolate (SIPI) was obtained using the method of alkaline extraction and isoelectric precipitation. The variables assessed for protein extraction were: defatted flour/solvent, $\mathrm{pH}$, temperature and time. The values which were obtained a maximum solubility were: 1:30, $11,50^{\circ} \mathrm{C}$ and $60 \mathrm{~min}$, respectively. Soluble proteins were precipitated at $\mathrm{pH} 6(\mathrm{pI})$, washed, brought to $\mathrm{pH} 7$ and spray dried. The techno-functionals properties of SIPI that had higher magnitudes compared with soy protein isolate (SPI) were: solubility (maximum $99,4 \%$ at $11 \mathrm{pH}$ and minimum 18,7\% at $6 \mathrm{pH}$ ), oil absorption capacity (1.39 g oil/g isolated), foaming capacity (55\% at $1 \%$ concentration and $\mathrm{pH} 8)$ and foam stability $(33,7 \%$ at $1 \%$ of concentration, pH 8 at $120 \mathrm{~min})$, emulsifying capacity $(59,1 \%)$ and those with lower magnitudes were: water holding capacity (1,84 g water/g isolated) and gelling capacity (15\%).
\end{abstract}

Key words: alkaline extraction, isoelectric precipitation, protein extraction.

\section{Introducción}

Las proteínas vegetales juegan un rol importante en la nutrición humana, particularmente en los países en desarrollo donde la ingesta promedio de proteínas es menor a la requerida. A causa de una inadecuada provisión de proteínas alimenticias, se investiga constantemente fuentes no convencionales de proteínas para su uso como ingredientes alimenticios tecno-funcionales y suplementos nutricionales (Onweluzo et al. 1995). La semilla de sacha inchi presenta un alto contenido de proteínas (27\%); esta proteína es rica en cistina, tirosina, treonina y triptófano (Hamaker et al. 1992) Las leguminosas tienen que ser procesadas antes de su consumo debido a su contenido de factores antinutricionales (Vidal-Valverde et al. 2002); estos factores pueden ser eliminados en los procesos de obtención de los aislados proteicos, procesos que se basan en la extracción alcalina y precipitación isoeléctrica (Khalid et al. 2003). Por otro lado, las proteínas de estas semillas deben poseer propiedades tecno-funcionales necesarias para su utilización con éxito, ya que afectan el comportamiento de los sistemas alimenticios a los cuales se adicionan, sea en el procesamiento o almacenamiento (Aremu et al. 2007). Las propiedades tecno-funcionales más interesantes en el procesamiento de los alimentos son: solubilidad, capacidad de retención de agua, capacidad de absorción de aceite, capacidad emulsificante, capacidad de formación de espuma y capacidad de gelificación (Boye et al. 2010a). Estas propiedades tecno-funcionales influyen en las características organolépticas y son esenciales en diferentes sistemas alimenticios tales como 
productos de confitería, bebidas, postres y productos cárnicos (Boye et al. 2010b). Los objetivos del presente estudio fueron la determinación de los parámetros físicoquímicos para la obtención de un aislado proteico a partir de torta de sacha inchi y la evaluación de sus propiedades tecno-funcionales.

\section{Materiales y métodos}

La torta de sacha inchi (ecotipo Pinto Recodo) obtenida en una empresa que procesa aceite, fue molida, tamizada $(0,25 \mathrm{~mm})$ y desgrasada (soxhlet) para obtener la harina desgrasada de sacha inchi (HDSI). Las proteínas totales fueron determinadas por el método de Kjeldhal y las proteínas solubles por el método espectrofotométrico de Biuret $(540 \mathrm{~nm})$. Para la obtención del aislado proteico de sacha inchi (APSI) se utilizó el método de extracción alcalina y precipitación ácida (Jayasena et al. 2010); para tal efecto se partió de los siguientes parámetros: $\mathrm{pH}$ (9); temperatura $\left(25 \pm 1^{\circ} \mathrm{C}\right)$; tiempo $(30 \mathrm{~min})$ (Eltayeb et al. 2011).

Extracción: La harina desgrasada fue mezclada con agua destilada (harina desgrasada/ agua destilada, $\mathrm{p} / \mathrm{v}$ : $1: 10,1: 15,1: 20,1: 25,1: 30,1: 35$ y $1: 40)$ y el $\mathrm{pH}$ de la suspensión fue ajustada utilizando $\mathrm{NaOH} 1 \mathrm{~N} ; \mathrm{pH}(9 ; 9,5$; $10 ; 10,5 ; 11 ; 11,5$ y 12$)$; temperatura $(25 ; 30 ; 40 ; 50 ; 60$ y $\left.70{ }^{\circ} \mathrm{C}\right)$ y tiempo $(20 ; 30 ; 40 ; 50 ; 60 ; 70$ y $80 \mathrm{~min})$. En cada una de las etapas las partículas insolubles fueron eliminadas, previa centrifugación a $4000 \mathrm{rpm}$ por $20 \mathrm{~min}$, y los sobrenadante fueron refrigerados a $4{ }^{\circ} \mathrm{C}$ hasta su uso.

Precipitación: Las proteínas extraídas fueron precipitadas con $\mathrm{HCl} 1 \mathrm{~N}$ a diferentes $\mathrm{pH}(2 ; 3 ; 4 ; 4,5 ; 5 ; 5,5 ; 6 ; 6,5: 7$ y 7,5); el precipitado fue recuperado por centrifugación a $4000 \mathrm{rpm}$ por $20 \mathrm{~min}$ y posteriormente lavado ( 2 veces) con una relación de precipitado/solvente 1:10 p/v. Para el primer lavado se utilizó una mezcla hidroalcohólica (alcohol/agua; 20/80, v/v) (Golcalves et al. 1997); para el segundo lavado se utilizó agua destilada (1:10 $\mathrm{p} / \mathrm{v}$ ). Después de cada lavado los precipitados fueron recuperados por centrifugación (4000 rpm por $20 \mathrm{~min}$ ). El precipitado fue recuperado mediante centrifugación (4000 rpm por $20 \mathrm{~min}$ ).

Atomización: La proteína precipitada fue ajustada a $\mathrm{pH}$ 7 y acondicionada a los parámetros: sólidos totales $12 \%$, temperatura del aire de entrada $160{ }^{\circ} \mathrm{C}$; temperatura de salida del aire $80^{\circ} \mathrm{C}$; temperatura de alimentación $25^{\circ} \mathrm{C}$ para su secado (Taboada, 1990).

\section{Propiedades tecno-funcionales}

Capacidad de Retención de Agua (CRA) (Beuchat, 1977). Se preparó una suspensión acuosa del aislado proteico al $10 \%(\mathrm{p} / \mathrm{v})$, en tubos de centrífuga y cada uno se agitó durante $30 \mathrm{~s}$ en un agitador vortex. El pH de cada suspensión se ajustó a un rango de 2-11, luego se agitó por 30 minutos en un agitador reciprocante a 25 ${ }^{\circ} \mathrm{C}$. Se centrifugó a $4000 \mathrm{rpm}$ por $15 \mathrm{~min}$. Los tubos de centrífuga se colocaron invertidos por una hora en una estufa a $50{ }^{\circ} \mathrm{C}$, el precipitado se pesó y el sobrenadante fue retenido para determinar la solubilidad de la proteína. La CRA se halló de la te. ecuación:

$$
C R A=\frac{\operatorname{Agua}(g)}{\text { aislado proteico }(g)}
$$

Solubilidad (SOL) (Butt y Batool, 2010). El sobrenadante que se obtuvo al momento de determinar la CRA, fue transferido a una fiola de $100 \mathrm{ml}$ y luego se enrasó con agua destilada. Se determinó el contenido de proteínas solubles por el método de Biuret.

Capacidad de Absorción de Aceite (CAA) (AOAC, 1990). Se mezcló $4 \mathrm{ml}$ de aceite de maíz con $0.5 \mathrm{~g}$ del aislado proteico seco en un tubo de centrífuga de 10 $\mathrm{ml}$. La mezcla se dejó reposar durante $30 \mathrm{~min}$ a $25^{\circ} \mathrm{C}$ y seguidamente se centrifugó (4000 rpm por $25 \mathrm{~min}$ ) descartándose el sobrenadante. La diferencia del peso del sedimento obtenido y el peso seco inicial proporcionó la cantidad de aceite retenido:

$$
\begin{aligned}
C A A & =\frac{\text { Aceite }(g)}{\text { aislado proteico }(g)} \\
\text { CAA }(\%) & =\frac{\text { Aceite }(g)}{\text { aislado proteico }(g)} \times 100
\end{aligned}
$$

Capacidad de Formación de Espuma (CFE) (Sosulski et al. 1976). Se preparó soluciones proteicas de 0.5, 0.75 y $1.0 \%$ y se ajustó el pH de cada solución a 6,7 y 8 , posteriormente se agitó por $5 \mathrm{~min}$ en una licuadora a máxima velocidad. Se calculó el porcentaje de volumen incrementado a los $30 \mathrm{~s}$ según la siguiente ecuación:

$\operatorname{CFE}(\%)=\frac{\text { Volumen }_{\text {después del batido }}-\text { Volumen }_{\text {antes del batido }}}{\text { Volumen }_{\text {antes del batido }}} \times 100$

Estabilidad de la Espuma (EES) (Sathe et al. 1982). Después de medir el volumen total del batido, se midió el volumen de la espuma en la probeta a un tiempo de 1, 10, 20, 30, 40, 50, 60 y 120 min determinándola en función del $\mathrm{pH}(6 ; 7$ y 8$)$ y de la concentración proteica $(0.5 ; 0.75$ y $1.0 \%$ ). Los resultados fueron calculados aplicando la siguiente ecuación:

$\operatorname{EES}(\%)=\frac{\text { Volumen de la espuma }}{\text { a un tiempo determinado }} \underset{\text { Volumen de la espuma }}{\text { aun tiempo cero }} \times 100$

Capacidad de Gelificación (CG) (Coffmann y García, 1977). Se preparó soluciones proteicas de 5, 10,15 y $20 \%(\mathrm{p} / \mathrm{v})$. Las soluciones se colocaron en tubos de ensayo y fueron calentadas a $90-95{ }^{\circ} \mathrm{C}$ en baño maría por $60 \mathrm{~min}$. Luego fueron enfriados a $4{ }^{\circ} \mathrm{C}$ por $60 \mathrm{~min}$. Los tubos fueron agitados para determinar la estabilidad del gel y aquellos conteniendo los geles estables fueron invertidos y dejados a temperatura ambiente por 30 min. Los resultados fueron reportados en términos de la menor concentración de muestra requerida para que el gel permanezca estable por 30 min a temperatura ambiente. 
Capacidad Emulsificante (CE) (Yasumatsu et al. 1972). Se mezcló $1 \mathrm{~g}$ de aislado proteico con $20 \mathrm{ml}$ de agua y se agitó durante $15 \mathrm{~min}$. El pH de la solución proteica se ajustó a 7 y se aforó a $25 \mathrm{ml}$ con agua destilada. Se mezcló los $25 \mathrm{ml}$ de esta solución proteica con $25 \mathrm{ml}$ de aceite de maíz en una licuadora por 3 min y posteriormente se centrifugó a $1300 \mathrm{rpm}$ por $5 \mathrm{~min}$. La CE se expresó en términos de porcentaje como la altura de la capa emulsificada con respecto al total del líquido.

Todas las determinaciones fueron hechas por triplicado y los resultados fueron analizados mediante un análisis de varianza $(P<0,05)$ y la significación de las diferencias entre las medias se determinaron por el test de rangos múltiples de TUKEY, con un nivel de significancia de $(P<0,05)$.

\section{Resultados y discusión}

\subsection{Obtención de la harina desgrasada de sacha inchi (HDSI)}

El Cuadro 1 muestra las diferencias entre la composición química proximal de la harina, la torta de sacha inchi (TSI) y el aislado proteico de sacha inchi (APSI). Respecto al contenido de proteínas de la TSI (47,09\%), ésta contiene una mayor cantidad de proteínas respecto al $40 \%$ aprox. de la harina de lupino (Hall y Johnson, 2004). El APSI tuvo un contenido proteico de $95 \%$ en base seca $(92,15 \%$ en b.h.), siendo mayor al contenido de lupino $(93,2 \%$ en b.s.) (Rodríguez-Ambriz et al. 2005).

\subsection{Obtención del aislado proteico de sacha inchi (APSI)}

\section{Extracción proteica}

Efecto de la relación harina desgrasada/solvente: La proteína fue extraída soluble en el sobrenadante y la mayor solubilidad de proteínas fue de $65,4 \%$ con una relación harina desgrasada/solvente 1:30, p/v (Fig.1-a) el incremento de las proteínas recuperadas fue significativamente diferente $(P<0,05)$ respecto a las otras relaciones de harina desgrasada /solvente. El porcentaje de proteínas extraídas se incrementó de 60,3 a 65,4\%, cuando la relación de harina desgrasada/solvente varió de 1:25 a 1:30. Reportes previos de extracción de proteínas de semillas de ajonjolí mostraron un $81 \%$ de recuperación de proteínas usando una relación 1:10 (p/v) (Jayasena et al. 2010).

Cuadro 1. Composición química proximal de la torta de sacha inchi (TSI), de la harina desgrasada de sacha inchi (HDSI) y del aislado proteico de sacha inchi (APSI).

\begin{tabular}{lccc}
\hline & TSI & HDSI & APSI \\
\hline Humedad (\%) & $12,36 \pm 0,03^{\mathrm{a}}$ & $9,42 \pm 0,05^{\mathrm{b}}$ & $3,01 \pm 0,06^{\mathrm{c}}$ \\
Proteína (\%) & $\mathbf{4 7 , 0 9} \pm \mathbf{0 , 4 5} \mathbf{6}^{\mathrm{a}} \mathbf{6 0 , 9 0} \pm \mathbf{0 , 0 7}^{\mathrm{b}}$ & $\mathbf{9 2 , 1 5} \pm \mathbf{0 , 0 4}^{\mathrm{c}}$ \\
Grasa (\%) & $18,22 \pm 0,09^{\mathrm{a}}$ & $0,40 \pm 0,03^{\mathrm{b}}$ & $0,12 \pm 0,02^{\mathrm{c}}$ \\
Fibra (\%) & $2,73 \pm 0,06^{\mathrm{a}}$ & $4,31 \pm 0,14^{\mathrm{b}}$ & $0,50 \pm 0,06^{\mathrm{c}}$ \\
Ceniza (\%) & $5,32 \pm 0,08^{\mathrm{a}}$ & $6,15 \pm 0,06^{\mathrm{b}}$ & $2,00 \pm 0,05^{\mathrm{c}}$ \\
Carbohidrato (\%) & $14.28 \pm 0,41^{\mathrm{a}}$ & $18.82 \pm 0,10^{\mathrm{b}}$ & $2.22 \pm 0,07^{\mathrm{c}}$ \\
\hline
\end{tabular}

Los valores son el promedio de tres repeticiones \pm desviación estándar.

Letras diferentes en la misma fila presentan diferencias significativas a un $\mathrm{p}<0,05$.

Efecto del pH: La mayor sulubilidad de proteínas (89,8\%) fue obtenida a pH 11 (Fig. 1-b), siendo significativamente diferente $(P<0,05)$ a la recuperación a otros pHs. El porcentaje de proteínas extraídas se incrementó de 82,6 a $89,8 \%$ cuando se cambió el pH de la solución de 10,5 a 11 y posteriormente disminuyó. El pH que correspondió a la máxima extracción de proteínas coincidió con el obtenido para la quinua (Abugoch et al. 2008).

Efecto de la temperatura: La mayor solubilidad de proteínas $(94,9 \%)$, fue obtenida con una temperatura de $50^{\circ} \mathrm{C}$ (Fig.1-c), siendo significativamente diferente $(P<0,05)$ a las recuperaciones obtenidas a otras temperaturas. El porcentaje de la proteína extraída se incrementó de 91,7 a 94,8\% cuando la temperatura se incrementó de 40 a $50^{\circ} \mathrm{C}$. La solubilidad disminuyó a temperaturas más elevadas.

Efecto del tiempo: La mayor solubilidad de proteínas (99,1\%) se alcanzó a un tiempo de 60 min (Fig.1-d), siendo significativamente diferente $(P<0,05)$ a las recuperaciones obtenidas a otros tiempos. El porcentaje de la proteína extraída se incrementó de 96,2 a 99,1\% cuando se varió el tiempo de 50 a 60 min. La solubilidad disminuyó a mayores tiempos. El tiempo de máxima extracción de proteínas coincidió con los resultados obtenidos por otro autores (Jayasena et al. 2010; Boye et al. 2010a) quienes trabajaron en lupino y habas, respectivamente.

\section{Precipitación isoeléctrica}

El punto isoeléctrico $(\mathrm{pI})$ de las proteínas del sacha inchi fue a $\mathrm{pH}$ 6, precipitando el 81,8\% (Fig.2). La solubilidad de las proteínas de sacha inchi precitadas a $\mathrm{pH} 6$ fue significativamente diferente $(P<0,05)$ a las obtenidas a los otros pHs estudiados. El porcentaje de proteínas $(18,2 \%)$ que permaneció soluble en su pI fue similar al obtenido para la harina de nuez de barinas (Caryodendron orinocense K.) (17,8\%) (Padilla et al.1996).

\subsection{Propiedades tecno-funcionales}

\subsubsection{Capacidad de retención de agua (CRA)}

El aislado proteico de sacha inchi mostró una menor CRA respecto al de soya a un rango de pH de 2 a 11 (Fig. 3). La CRA tiene una relación directa con el contenido de aminoácidos polares presentes (Yusuf et al. 2008) en la proteína, lo que sugiere que el APSI tiene menor número de aminoácidos polares que el APS. 

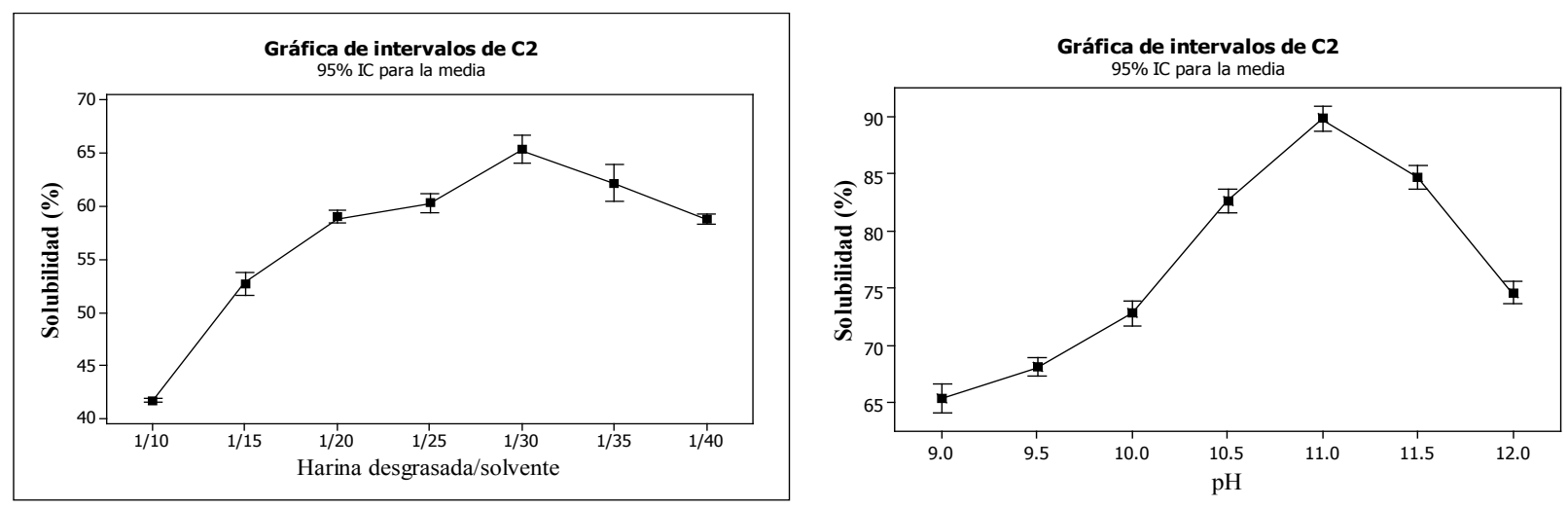

(a)

(b)


(d)

Figura 1. El efecto de: (a) relación harina desgrasada/solvente; (b) pH; (c) temperatura y (d) tiempo, sobre la solubilidad de las proteínas de la harina desgrasada de sacha inchi.

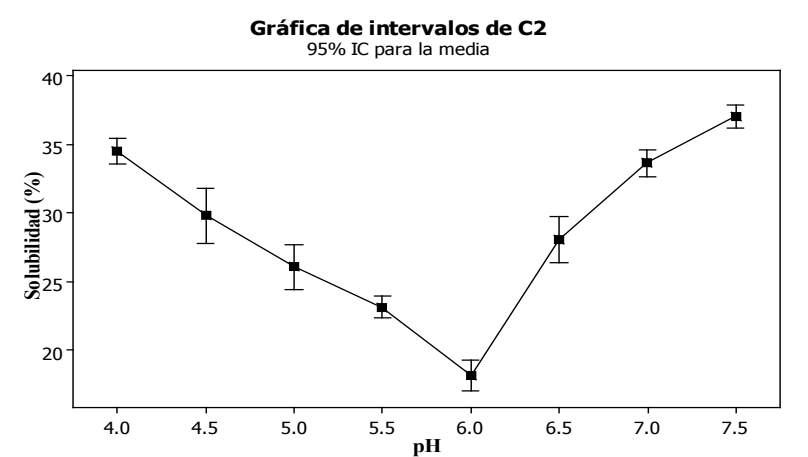

Figura 2. Determinación del punto isoeléctrico $(\mathrm{pI})$ de la proteína de sacha inchi.

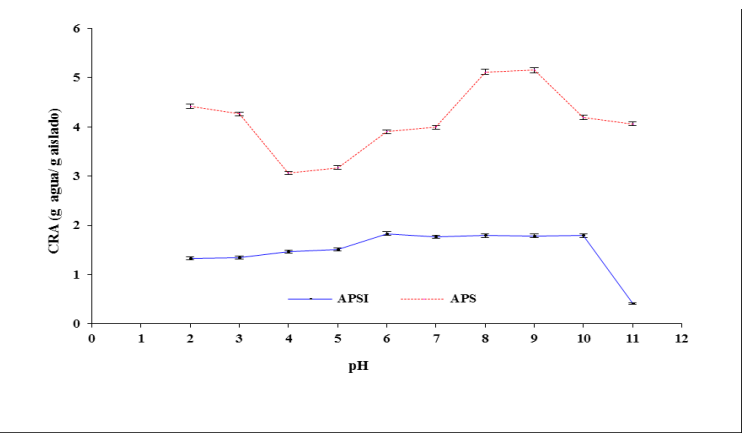

Figura 3. Determinación de la CRA de los aislado proteico de sacha inchi (APSI) y aislado proteico de soya (APS).

\subsubsection{Solubilidad (SOL)}

La Fig. 4 muestra las curvas de SOL, tanto de las proteínas de sacha inchi, como de las de soya a diferentes niveles de $\mathrm{pH}$. La proteína de sacha inchi presentó una mínima SOL $(18,7 \%)$ a pH $6(\mathrm{pI})$ y la máxima $\mathrm{SOL}(99,4 \%)$ a $\mathrm{pH} 11$; mientras que la proteína de soya presentó una mínima SOL $(11,3 \%)$ a $\mathrm{pH} 4,5$ y una máxima $\mathrm{SOL}(85,2 \%)$ a $\mathrm{pH} 9,5$. El pH para obtener la mínima SOL, para otros productos como arveja, habas y soya, ha sido reportado en un rango de 4 a 6 (Fernández-Quintela et al. 1997). El perfil de SOL de la proteína de sacha inchi fue significativamente diferente $(\mathrm{P}<0,05)$ al de la soya, en un rango de $\mathrm{pH}$ de 2 a 12 , lo que podría atribuirse a su menor composición de aminoácidos polares (Padilla et al. 1996).

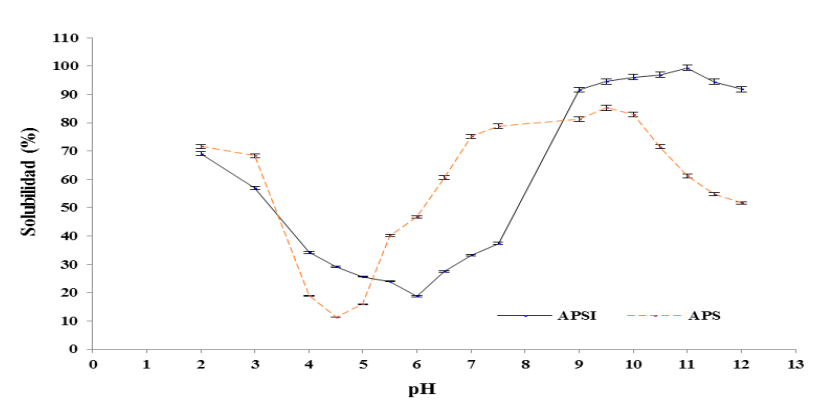

Figura 4. Perfil de solubilidad del APSI (aislado proteico de sacha inchi) y APS (aislado proteico de soya). 


\subsubsection{Capacidad de absorción de aceite (CAA)}

En el Cuadro 2 se puede observar que el APSI presenta mayor CAA respecto al APS $(1,39$ y $0,85 \mathrm{~g}$ aceite/g aislado proteico, respectivamente), existiendo diferencias significativas $(P<0,05)$ entre ellos. La cadena de proteínas que tiene un elevado número de terminales no polares contribuye a incrementar la CAA (FernándezQuintela, et al. 1997), lo que sugiere que la cadena de la proteína de sacha inchi tiene un mayor número de terminales no polares debido a su mayor CAA respecto a la proteína de soya. La CAA del APSI y del APS se presenta en el Cuadro 2. Esta capacidad de las proteínas de enlazar lípidos es muy importante para la formulación de productos para freír y para la retención de los sabores; asimismo disminuye el desarrollo de la rancidez oxidativa y en consecuencia aumenta la estabilidad durante el almacenamiento (Sathe et al. 1982). Como los puntos vulnerables de los ácidos grasos están cubiertos o bloqueados por terminales lipofílicos de las proteínas, no serán atacados fácilmente por los compuestos oxidantes disminuyendo así la rancidez oxidativa (Kristinsson y Rasco 2000, Jung y Johnson 2005, Belén et al. 2007). Un aislado proteico tiene una excelente CAA si alcanza un valor de 300\% (Yusuf et al. 2008), al respecto, el APSI tiene una CAA próxima a este valor (271\%), por lo que podría ser utilizado en la elaboración de productos que demandan alta CAA.

\subsubsection{Capacidad de formación de espuma (CFE) y estabilidad de la espuma (EES)}

La CFE del APSI fue dependiente del $\mathrm{pH}$ y de la concentración (Fig. 5). Las magnitudes más bajas de la CFE del APSI se manifestaron en su $\mathrm{pI}(\mathrm{pH} \mathrm{6)}$; al respecto, cuando el $\mathrm{pH}$ se aproxima a su pI la carga neta de las proteínas es mínima por lo que es menos soluble y tiene menos flexibilidad para desarrollarse la espuma, lo que lleva a un aumento de la tensión superficial. Por lo tanto, menos proteína es adsorbida en la interfase aireagua, lo que lleva a una reducción de la CFE (Khalid et al. 2003; Mashair et al. 2006). Esta propiedad fue comparada a diferentes $\mathrm{pHs}$ y concentraciones de aislado proteico, mostrando diferencias significativas $(P<0,05)$. Por otro lado, hubo una relación directa entre el $\mathrm{pH}$ y la CFE del APSI; al respecto, cuando el $\mathrm{pH}$ aumenta hacia la región alcalina la carga neta de la proteína es mayor aumentando la interacción molecular, lo que se traduce en una mejora de la CFE. Similar comportamiento se observó para el APS, pero en menor magnitud.
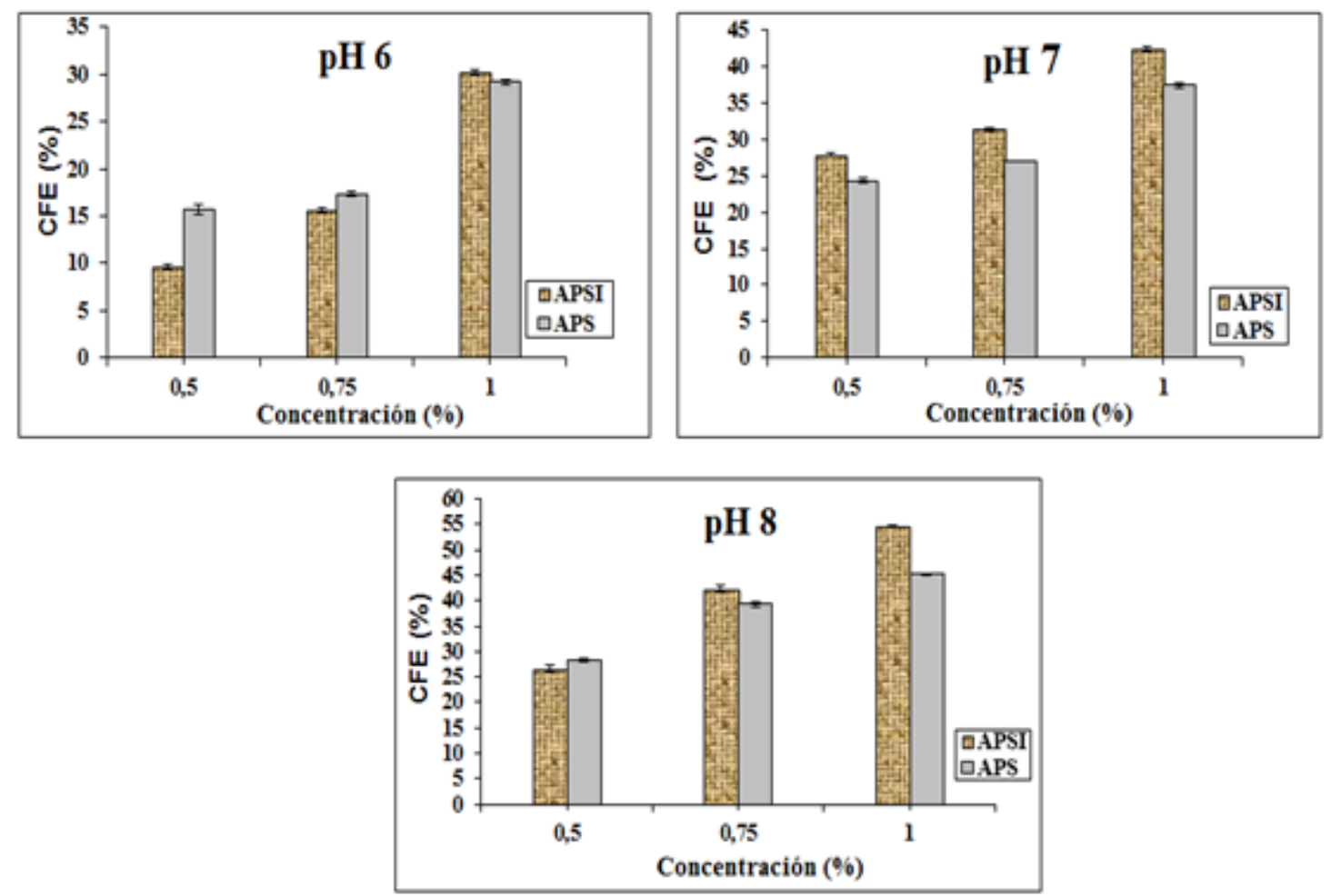

Figura 5. Determinación de la capacidad de formación de espuma (CFE) del aislado proteico de sacha inchi (APSI) y del aislado proteico de soya (APS), a diferentes pHs y concentraciones. 

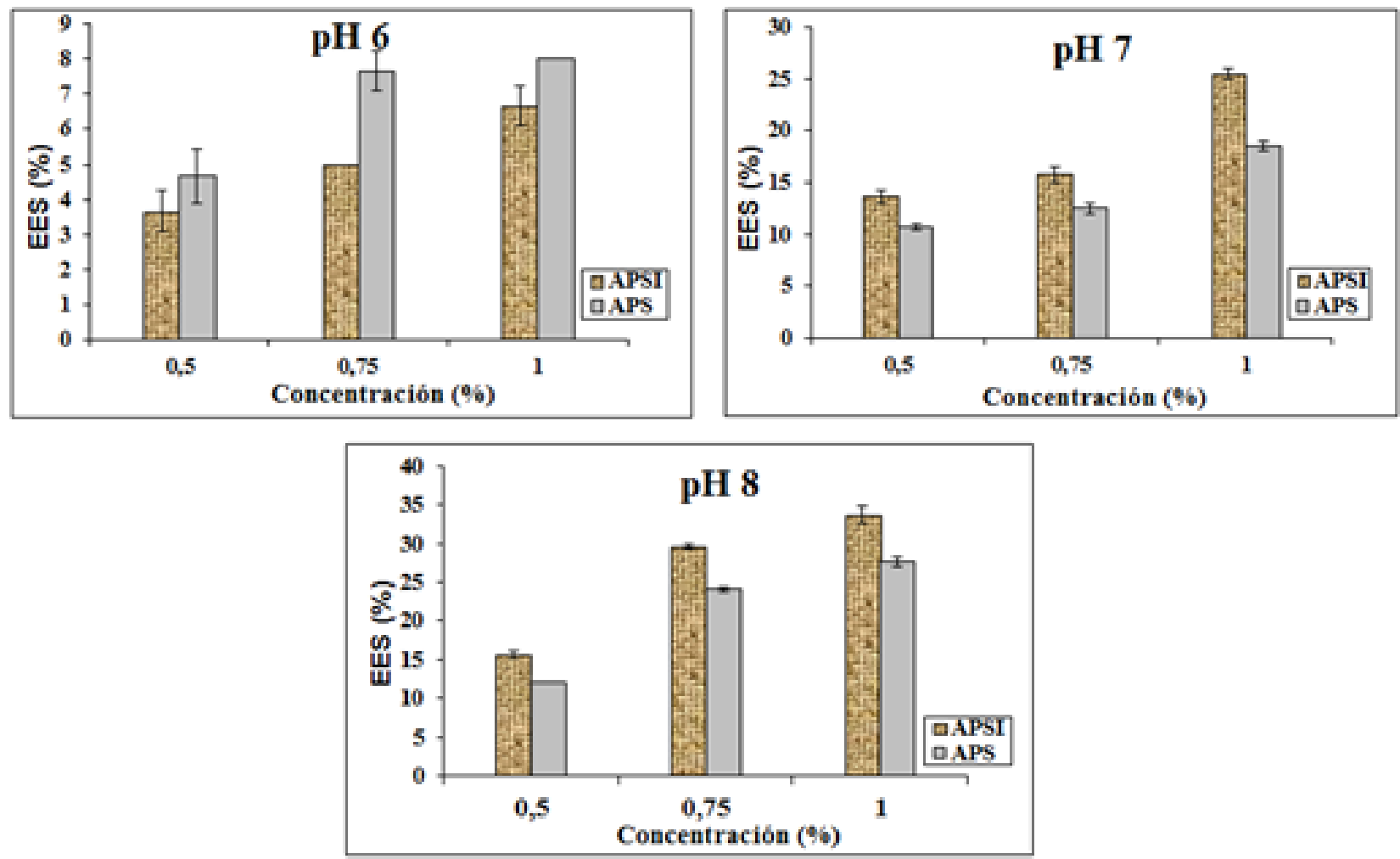

Figura 6. Determinación de la estabilidad de la espuma (EES) del aislado proteico de sacha inchi (APSI) y del aislado proteico de soya (APS), a diferentes pHs y concentraciones.

Cuadro 2. Capacidad de Absorción de Aceite (CAA) del aislado proteico de sacha inchi (APSI) y aislado proteico de soya (APS).

\begin{tabular}{ccc}
\hline Muestra & CAA $(\mathrm{g}$ aceite/ g aislado $)$ & CAA $(\%)$ \\
\hline APSI & $2,710 \pm 0,00^{\mathrm{b}}$ & $271,04 \pm 0,37^{\mathrm{b}}$ \\
APS & $1,658 \pm 0,01^{\mathrm{a}}$ & $165,84 \pm 0,25^{\mathrm{a}}$
\end{tabular}

Los valores son el promedio de tres repeticiones \pm desviación estándar. Letras diferentes en la misma columna presentan diferencias significativas

a un $P<0,05$

La EES del APSI presentó una menor magnitud en su $\mathrm{pI}(\mathrm{pH}$ 6) incrementándose a pHs mayores a su pI (Fig. 6); al respecto, trabajos anteriores han confirmado que la espuma es más estable a pHs alejados al pI de la proteína (Mashair et al. 2006).

\subsubsection{Capacidad de gelificación (CG)}

Para que el APSI forme un gel estable se necesitó una concentración de $15 \%$, mientras que APS sólo necesitó un $10 \%$ (Fig. 7). La concentración mínima para gelificar proteínas de distintas leguminosas oscila entre 12 a $14 \%$ (Mashair et al. 2006); pero para el caso del caupí y frijol mungo se ha reportado un valor de 16\% (Dench et al. 1981). Asimismo, el APSI mostró una baja CG y baja CRA, lo que está de acuerdo con trabajos realizados anteriormente que mencionan que la CG y la CRA están directamente relacionadas (Wilton et al. 1997).

\subsubsection{Capacidad emulsificante (CE)}

El APSI presentó mayor CE $(59,11 \%)$ respecto al APS $(55,81 \%)$ a un mismo pH (7) (Fig. 8), existiendo diferencias significativas $(\mathrm{P}<0,05)$ entre los dos. Esta mayor $\mathrm{CE}$ sugiere, al igual que en la CAA, la mayor presencia de grupos no polares en la cadena de proteínas (Padilla et al. 1996) del APSI respecto al APS.


Figura 7. Determinación de la capacidad de gelificación (CG) del aislado proteico de Sacha inchi (APSI) y el aislado proteico de soya (APS) a diferentes concentraciones. 


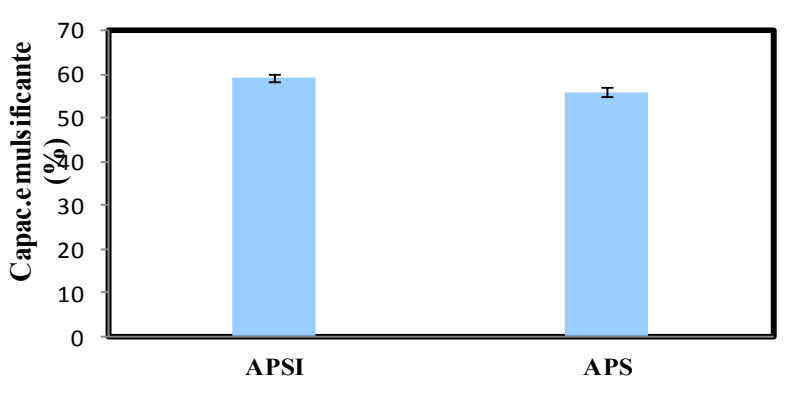

Figura 8. Capacidad emulsificante (CE) de aislado proteico de Sacha Inchi (APSI) y del aislado proteico de soya (APS).

\section{Conclusiones}

La mayor extracción de proteínas de sacha inchi se obtuvo con los siguientes parámetros: 1/30 (harina desgrasada/solvente); $11(\mathrm{pH}) ; 50{ }^{\circ} \mathrm{C}$ (temperatura) y 60 min (tiempo). La máxima precipitación de proteínas fue a $\mathrm{pH}$ 6. Las mejores propiedades tecno-funcionales del APSI, respecto al APS, fueron: CAA, CFE, EES y CE por lo que puede ser utilizada en la elaboración de embutidos, mayonesa, helados, entre otros productos alimenticios.

\section{Literatura citada}

Abugoch, L. E.; Romero, N.; Tapia, C. R.; Silva, J. and Rivera, M. 2008. Study of some physicochemical and functional properties of quinoa (Chenopodium quinoa Willd) protein isolates. Journal of Agricultural and Food Chemistry 56(12): 4745-4750.

AOAC. 1990. Official Methods of Analysis, 13th edition. Association of Official Analytical Chemists. Washington DC USA 684.

Aremu, M. O.; Olaofe, O. and Akintayo, E. T. 2007. Functional properties of some Nigerian varieties of legume seed flours and flour concentration effect on foaming and gelation properties. Journal of Food Technology 5(2): 109-115.

Belén D. R.; Moreno, M. J.; García, D.; Medina, C. y Sidorovas, A. 2007. Caracterización de un hidrolizado proteico enzimático obtenido del pez caribe colorado (pygocentrus cariba humboldt, 1821). Interciencia. v.32 n.3 Caracas.

Beuchat, R. 1977. Functional and electrophoretic characteristics of succinylated peanut flour protein. Journal of Agriculture and Food Chemistry 25: 258-261.

Boye, J.; Aksay, S.; Roufik, S.; Ribéreau, M.; Mondor, M. and Farnworth, E. 2010a .Comparison of the functional properties of pea, chickpea and lentil protein concentrates processed using ultrafiltration and isoelectric precipitation technological. Food Research International 43(2): 537-548.

Boye, J.; Zare, F. and Pletch, A. 2010b. Pulse proteins: Processing, characterization, functional properties and applications in food and feed. Food Researched
International 43(2): 414-431.

Butt, M. S. y Batool R. 2010. Nutritional and functional properties of some promising legumes protein isolates. Pakistan Journal of Nutrition 9:373-379.

Coffmann, C. W. and García, V. V. 1977. Functional properties and amino acid content of a protein isolate from mung bean flour. International Journal of Food Science \& Technology 12(5): 473-484.

Dench, J. E.; Rivas, N. R. and Caygill, J. C. 1981. Selected functional properties of sesame (Sesamum indicum) flour and two protein isolates. Journal of the Science of Food and Agriculture 32:557-564.

Eltayeb, A.; Ali, O.; Arab, A. and Salem, F. 2011. Chemical composition and functional properties of flour and protein isolate extracted from Bambara groundnut (Vigna subterranean). African Journal of Food Science 5(2): 82- 90 .

Fernandez-Quintela, A.; Macarulla, M. T.; Del Barrio, A. S. and Martínez, J. A. 1997. Composition and functional properties of protein isolates obtained from commercial legumes grown in northern Spain. Plant Foods for Human Nutrition 51: 331-342.

Golcalves, N.; Vioque, J.; Clemente, A.; SánchezVioque, R.; Bautista, J. y Millán, F. 1997. Obtención y caracterización de aislados proteicos de colza. Grasas y Aceites. Pesquisa Agropecuaria Brasileira 48: 282-289.

Hall, R. S., and Johnson, K.S. 2004. Sensory acceptability of foods containing Australian sweet lupin (Lupinus angustifolius) flour. Journal of Food Science 69(2): 92-97.

Hamaker, BR.; Valles, C.; Gilman, R.; Hardmeier, RM.; Clark, D.; García, HH.; González, AE.; Kohlstad, I.; Castro, M.; Valdivia, R.; Rodriguez, T. and Lescano, M. 1992. Amino Acid and Fatty Acid Profiles of The Inca Peanut (Plukenetia volubilis). American Association of General Chemistry 69(4): 461463.

Jayasena, V.; Chih, H. J. and Nasar-Abbas, S. M. 2010. Functional properties of sweet Lupin protein isolated and tested at various $\mathrm{pH}$ levels. Research Journal of Agriculture and Biological Sciences 6(2): 130-137.

Jung, S,; Murphy and PA., Johnson, LA. 2005. Physicochemical and functional properties of soy protein substrates modified by low levels of protease hydrolysis. J. Food Sci. 70: 180-187.

Khalid, E. K.; Babiker, E. E. and El Tinay, A. H. 2003. Solubility and functional properties of sesame seed proteins as influenced by $\mathrm{pH}$ and/or salt concentration. Food Chemistry 82: 361-366.

Kristinsson, HG. and Rasco, BA. 2000. Fish protein hydrolysates: production, biochemical, and functional properties. Crit. Rev. Food Sci. Nutri. 40: 43-81.

Mashair, S.; Abdullahi, E. T.; Abd, E.; Elfadil, B. and Elhadi, E. 2006. Solubility as influenced by $\mathrm{pH}$ and $\mathrm{NaCl}$ Concentration and functional properties of lentil proteins 
isolate. Pakistan Journal of Nutrition 5(6): 589-593.

Onweluzo, J,; Onuoha, K. and Obanu, Z. A. 1995. Comparative study of some functional properties of Afzelia africana and Glycine max flours. Food Chemistry 54 (1): $55-59$.

Padilla, F. C.; Alvarez, M. T.; Alfaro, M. J.; Macarulla, M. T.; Del Barrio, A. S. and Martínez, J. A. 1997. Composition and functional properties of protein isolates obtained from commercial legumes grown in northern Spain. Plant Foods for Human Nutrition 51(4): 331-341.

Padilla, F. C.; Alvarez, M.,T. and Alfaro, M. J. 1996. Functional properties of Barinas nut flour (Caryodendron orinocense Karst. Euphorbiaceae) compared to those of soybean. Food Chemistry 57:191-196.

Rodríguez-Ambriz, S. L.; Martínez-Ayala, A. L.; Millán, F. and Dávila-Ortíz, G. 2005. Composition and functional properties of Lupinus campestris protein isolates. Plant Foods for Human Nutrition 60(3): 99-107.

Sathe, S. K.; Deshpande, S. S. and Salunkhe, D. K. 1982. Functional properties of lupin seed (Lupinus mutabilis) proteins and protein concentrates. Journal of Food Science 47:491-497.

Sosulski, F. W.; Humbert, E. S.; Bui, K, and Jones, J. O. 1976. Functional properties of rapeseed flour concentrates and isolates. Journal of Food Science 41:1348-1354.

Taboada, M. 1990. Evaluación de las propiedades funcionales de un aislado proteico de germen de quinua (Chenopodium quinoa Wild.) desgrasado. Tesis Ing. UNALM. Lima-Perú.

Vidal-Valverde, C.; Frías, J.; Sierra, I.; Blazquez, I.; Lambien, F. and Kuo, Y. H. 2002. New functional legume food by germination: Effect on the nutritive value of beans, lentils and peas. Eu. Food Res. Tec 215:472476.

Wilton, P.; Larry, R.; Beuchat, K. and Dixon, P. 1997. Functional properties of cowpea (Vigna unguiculata) flour as affected by soaking, boiling and fungal fermentation. Journal of Food and Science 45: 480-486.

Yasumatsu, K.; Sawada, K.; Moritaka, S.; Misaki, M.; Toda, J.; Wada, T. and Ishii, K. 1972. Whipping and emulsifying properties of soyabean products. Agric. Biol. Chem 36: 719-728.

Yusuf, A.; Ayedun, H. and Sanni, L. 2008. Chemical composition and functional properties of raw and roasted Nigerian benniseed (Sesamum indicum) and Bambara groundnut (Vigna subterranean). Food Chemistry 111(2): 277-282. 